\title{
Calendrier des activités (de juillet 2009 à septembre 2010)
}

\section{(2) OpenEdition}

12 Journals

Édition électronique

URL : https://journals.openedition.org/cem/11254

DOI : 10.4000/cem. 11254

ISSN : 1954-3093

Éditeur

Centre d'études médiévales Saint-Germain d'Auxerre

Édition imprimée

Date de publication : 15 août 2009

ISSN : 1623-5770

Référence électronique

"Calendrier des activités (de juillet 2009 à septembre 2010) ", Bulletin du centre d'études médiévales d'Auxerre | BUCEMA [En ligne], 13 | 2009, mis en ligne le 15 septembre 2009, consulté le 22 septembre 2022. URL : http://journals.openedition.org/cem/11254; DOI : https://doi.org/10.4000/cem.11254

Ce document a été généré automatiquement le 22 septembre 2022.

\section{cc) (†) (2)}

Creative Commons - Attribution - Pas d'Utilisation Commerciale - Partage dans les Mêmes Conditions 4.0 International - CC BY-NC-SA 4.0

https://creativecommons.org/licenses/by-nc-sa/4.0/ 


\section{Calendrier des activités (de juillet 2009 à septembre 2010)}

\section{Année 2009}

\begin{tabular}{|c|c|}
\hline $\begin{array}{l}24-25 \\
\text { septembre }\end{array}$ & $\begin{array}{l}\text { Auxerre - Productions, remplois, mises en registre : la pratique sociale de l'écrit à } \\
\text { travers la documentation médiévale bourguignonne. Marie-José GASSE-GRANDJEAN et } \\
\text { Eliana MAGNANI }\end{array}$ \\
\hline $\begin{array}{l}15-17 \\
\text { octobre }\end{array}$ & $\begin{array}{l}\text { Auxerre - Le bois dans l'architecture et l'aménagement de la tombe : quelles } \\
\text { approches? Florence CARRE et Fabrice HENRION }\end{array}$ \\
\hline $\begin{array}{l}20-21 \\
\text { novembre }\end{array}$ & $\begin{array}{l}\text { Auxerre - Les objets sous contrainte. Gages, saisies, confiscation, vol, pillage, recel... } \\
\text { Laurent FELLER }\end{array}$ \\
\hline $\begin{array}{l}27-28 \\
\text { novembre }\end{array}$ & Autun - Les domus ecclesiae : aux origines des palais épiscopaux. Sylvie BALCON-BERRY \\
\hline $\begin{array}{l}27-28 \\
\text { novembre }\end{array}$ & $\begin{array}{l}\text { Auxerre - Les nouveaux horizons de l'ecclésiologie: histoire d'une discipline et } \\
\text { problèmes de méthode en Histoire de l'Église. Dominique IOGNA-PRAT }\end{array}$ \\
\hline
\end{tabular}

\section{Année 2010}

\begin{tabular}{|l|l|}
\hline 29 janvier & $\begin{array}{l}\text { Dijon - CBMA. Chartae Burgundiae Medii Aevi IV. Études, éditions, historiographie. } \\
\text { Marie-José GASSE-GRANDJEAN et Eliana MAGNANI }\end{array}$ \\
\hline 14-15 mai & $\begin{array}{l}\text { Cluny- Constructions, reconstructions et commémorations clunisiennes, 1790-2010. } \\
\text { Didier MÉHU }\end{array}$ \\
\hline 24-26 juin & $\begin{array}{l}\text { Romainmôtier - I. Cluny, le monachisme et l'Église. Anne BAUD, Dominique IOGNA- } \\
\text { PRAT, Eliana MAGNANI, Pierre-Alain MARIAUX, Jean-Daniel MOREROD, Isabelle ROSÉ, Daniel } \\
\text { RUSSO et Christian SAPIN }\end{array}$ \\
\hline
\end{tabular}


9-11

septembre
Cluny - II. Cluny, le monachisme et l'émergence d'une société seigneuriale. Anne BAUD, Dominique IOGNA-PRAT, Eliana MAGNANI, Pierre-Alain MARIAUX, Jean-Daniel MOREROD, Isabelle ROSÉ, Daniel RUSSO et Christian SAPIN

3

\section{Contact : cnrs.cem@wanadoo.fr}

